\title{
Noise Influence on Damage Detection through Modal State Observers Methodology
}

A.A. CAVAlini Jr., V.R. FRANCO ${ }^{2}$, C.G. GONSALEZ ${ }^{3}$, V. LOPES Jr. ${ }^{4}$ G.P. $\mathrm{DE} \mathrm{MELO}^{5}$, GMSINT - Grupo de Materiais e Sistemas Inteligentes, Department of Mechanical Engineering, FEIS, UNESP, Av. Brasil 56, 15385-000 Ilha Solteira, SP, Brazil.

\begin{abstract}
Noise effect on damage detection methodologies is an important matter. The probability of false diagnosis can be minimized when the noise influence is taken into account. In this paper, the noise effect in the damage detection approach is evaluated using state observers based on modal data. The paper concludes with a numerical application in a plane truss structure considering noise effect in the input signals.
\end{abstract}

Keywords. Noise Influence, Modal State Observers, Damage Detection.

\section{Introduction}

The detection of deterioration and damage in many different kinds of engineering systems has already begun to move from the laboratory to the field. Structural health monitoring (SHM) is an emerging research area with multiple applications. Many aerospace and civil infrastructure systems are at or beyond of their design life; however, it is envisioned that they will remain in service for an extended period. Another potential SHM application is in new systems. Not surprisingly, the SHM of aerospace structures have one of the highest investments for SHM applications, since damage can lead to catastrophic and expensive failures, and the vehicles involved undergo regular costly inspections. Currently $27 \%$ of an average aircraft's life cycle cost, both for commercial and military vehicles, is spent on inspections and repairs. This cost excludes the opportunity cost associated with the time the aircraft is grounded for scheduled maintenance $[5,7,14]$.

One general way of damage detection, based on SHM, consists in compare states of the structure in different periods. The dynamic properties change if damages occur in the structure. This paper is addressed to SHM technology integrating the features of state observers. State observers can reconstruct the states that were not measured directly in the structure or can estimate the motion of the system

\footnotetext{
${ }^{1}$ aacjunior@aluno.feis.unesp.br

${ }^{2}$ vrfranco@aluno.feis.unesp.br

${ }^{3}$ cggonsalez@aluno.feis.unesp.br

4 vicente@dem.feis.unesp.br

${ }^{5}$ gilberto@dem.feis.unesp.br
} 
that cannot be measured directly $[3,6,9]$. The observer concept for a dynamic systems was introduced by Luenberger in 1964 with the demonstration of how the known inputs and outputs of a system can be used to construct an estimative of the system state vector. This dispositive of state reconstruction was called Luenberger Observer. The complete demonstration of the state vector reconstruction, for a linear system, was presented by Luenberger (1966).

Methodologies of damage detection in mechanical system involving state observers have been developed in the last years $[12,13]$. Different techniques can be applied for damage detection, as for instance, that one using methodologies in the modal domain, based on modal forms of the structure (Maia, 2003). Novel approaches associate state observers in modal domain for identifying vibration modes that are more affected with damage presence $[1,2]$. The contribution of this paper lies in the analysis of the noise influence for damage detection in order to propose a novel robust technique.

\section{Structural Modeling}

The proposed approach is demonstrated theoretically through an analytical model. It is possible to describe the dynamical behavior of a structure in terms of mass, stiffness and damping matrices, and displacement and velocity vectors, shown in equations (2.1) and (2.2).

$$
\begin{gathered}
\ddot{q}(t)+M^{-1} D_{a} \dot{q}(t)+M^{-1} K q(t)=M^{-1} B_{o} u(t) \\
y(t)=C_{o q} q(t)+C_{o v} \dot{q}(t)
\end{gathered}
$$

where $q(t)$ is the $n$-length displacement vector, $u(t)$ is the $s$-length input vector, $y(t)$ is r-length output vector, $M$ is the $n \times n$ mass matrix, $D_{a}$ is the $n \times n$ damping matrix, and $K$ is the $n \times n$ stiffness matrix. $B_{o}$ is the $n \times s$ input matrix, $C_{o q}$ is the $r \times n$ output displacement matrix, and $C_{o v}$ is the $r \times n$ output velocity matrix. The mass matrix is positive definite, and the stiffness and damping matrices are positive semi-definite, $n$ is the number of degrees of freedom of the system (linearly independent coordinates describing the finite-dimensional structure), $r$ is the number of outputs and $\mathrm{s}$ is the number of inputs. Using the classic procedure of modal analysis [11], it is possible to write the equations of motion in modal coordinates, $q_{m}(t)$. Thus, the modal model of second order is given by:

$$
\begin{gathered}
q(t)=\Phi q_{m}(t) \\
\ddot{q}(t)+2 Z \Omega \dot{q}_{m}(t)+\Omega q_{m}(t)=B_{m} u(t) \\
y(t)=C_{m q} q_{m}(t)+C_{m v} \dot{q}_{m}(t)
\end{gathered}
$$

where $\Omega$ is the modal matrix and $Z$ is the matrix of damping coefficients $\left(\zeta_{i}\right)$, given by equation (2.6).

$$
Z=0,5 M_{m}^{-1} D_{m} \Omega^{-1}=0,5 M_{m}^{-1 / 2} K_{m}^{-1 / 2} D_{m}
$$


where $\Omega^{2}=M_{m}^{-1} K_{m}$ is the matrix of natural frequencies.

The matrices $M_{m}, K_{m}$ and $D_{m}$ (equations (2.7), (2.8) and (2.9)) are diagonal matrices of modal mass, stiffness and damping, respectively, which are given by:

$$
\begin{aligned}
& M_{m}=\Phi^{T} M \Phi \\
& K_{m}=\Phi^{T} K \Phi \\
& D_{m}=\Phi^{T} D_{a} \Phi
\end{aligned}
$$

The matrix $D_{a}$ (equation (2.10)) is assumed to be proportional to mass and stiffness matrices, so that:

$$
D_{a}=\alpha M+\beta K
$$

with $\alpha$ and $\beta$ constants. Matrix $B_{m}$ in equation (2.4) is the input modal matrix, or participation modal matrix and is given by equation (2.11).

$$
B_{m}=M_{m}^{-1} \Phi^{T} B_{o}
$$

$C_{m q}$ and $C_{m v}$ (equations (2.12) and (2.13), respectively) are the output displacement and velocity modal matrices.

$$
\begin{gathered}
C_{m q}=C_{o q} \Phi \\
C_{m v}=C_{o v} \Phi
\end{gathered}
$$

The motion equations, (2.4) and (2.5), can be written in state space form by vectormatrix format through the triple $(A, B, C)$. It allows the equations to be manipulated more easily.

$$
\begin{gathered}
\dot{x}(t)=A x(t)+B u(t) \\
y(t)=C x(t)
\end{gathered}
$$

where $x(t)$ is the state vector, $A$ is the dynamic matrix, $B$ is the input matrix, $u(t)$ is the input force, $y(t)$ is the output vector and $C$ is the output matrix. The related matrices $A, B$ and $C$ are given by:

$$
\begin{gathered}
A=\left[\begin{array}{cc}
0 & I \\
-\Omega^{2} & -2 Z \Omega
\end{array}\right] \\
B=\left[\begin{array}{c}
0 \\
B_{m}
\end{array}\right] \\
C=\left[\begin{array}{ll}
C_{m q} & C_{m v}
\end{array}\right]
\end{gathered}
$$

The equations (2.14) and (2.15) are not in modal state representation (although it was obtained using modal displacements, $\left.q_{m}\right)$. The modal state-space representation has a triple $\left(A_{m}, B_{m}, C_{m}\right)$ characterized by the block-diagonal dynamic matrix, $A_{m}$ in equation (2.19), and the related input and output matrices, equations (2.20) and (2.21), respectively [4].

$$
A_{m}=\operatorname{diag}\left(A_{m i}\right)
$$




$$
\begin{gathered}
B_{m}=\left[\begin{array}{c}
B_{m 1} \\
B_{m 2} \\
\vdots \\
B_{m n}
\end{array}\right] \\
C_{m}=\left[\begin{array}{llll}
C_{m 1} & C_{m 2} & \cdots & C_{m n}
\end{array}\right]
\end{gathered}
$$

where $i=1,2, \cdots, n ; A_{m i}, B_{m i}$ and $C_{m i}$ are $2 \times 2,2 \times s$ and $r \times 2$ blocks, respectively. These blocks can take several different forms and also it is possible to convert from one form to another by a linear transformation.

\section{State Observers}

Some methods of damage detection are based on changes of the physical properties of the mechanical system, as for instance, variation of the stiffness. These factors result in variation in the dynamic response. Therefore, damage can be detected on-line by monitoring some features of the structure.

A state observer, for the original dynamic system $S(x ; y ; u)$ with state $x$, output $y$ and input $u$, is an auxiliary dynamic system $S^{\prime}\left(x^{\prime} ; z ; y ; u\right)$ with the following property: the output $x^{\prime}$ converges to state $x$ of the $S$ system, independently of the input $u$ and of the state $x$, as shown in figure (1). It's possible to construct the state

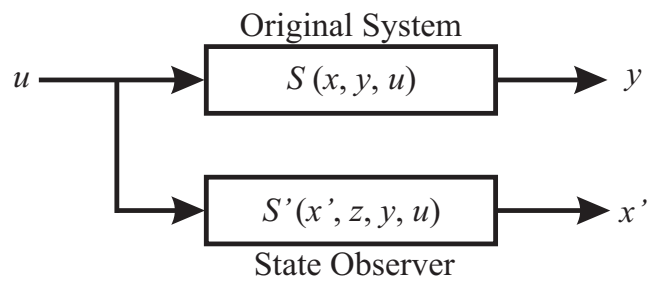

Figure 1: State observer definition.

observer if the original system is observable or detectable. $S$ is a physical system; $S^{\prime}$ is abstract and implemented by computer program.

\subsection{Modal State Observers}

There are some damage detection methodologies based on modal domain. Recently, a new methodology was proposed using modal state observers [1,2]. This approach associates the already known state observers with features obtained in modal domain. The states of the mechanical system are estimated in modal coordinates. An important observation is that the Modal State Observer can estimate the modal state vector that refers to the point where the output signals were measured in the structure.

The modal state observer is defined from the open loop observer construction shown in equation (3.1). Consider a linear original system, invariable in the time 
and observable $[6,12]$.

$$
\dot{\bar{q}}_{m}(t)=\left(\left[A_{m}\right]-[L]\left[C_{m}\right]\right) \bar{q}_{m}(t)+\left[B_{m}\right] u(t)+[L] y(t)
$$

where $\bar{q}_{m}(t)$ is the reconstructed output modal vector and $[L]$ is the gain of the observer. Many methods can be used for obtaining the gain matrix depending of the applied situation. The most used methods include the Kalman Filter (KF) and Linear Quadratic Regulator (LQR). In this paper, the gain was obtained by LQR due to its easier implementation and utilization comparing to other methods.

\section{Numerical Application}

The proposed methodology was numerically applied in a steel plane truss structure discretized by FEM (Finite Element Method) with 17 beam elements and 10 nodes, considering two degrees of freedom per node, as shown in figure (2). The values of physical and geometric parameters are given in Tab. (1). It was considered $2 \%, 5 \%$ and $8 \%$ of the input signal energy like white noise. The input excitation was applied by a sinusoidal force with $30 \mathrm{~Hz}$ located on node 10 (negative direction of axe $\mathrm{y}$ ). Two sensors were used, separately, for the data acquisition: sensor A - between the nodes 7 and 9 ; sensor $\mathrm{B}$ - between the nodes 5 and 6 . The damage was simulated by $20 \%$ of stiffness reduction located in the element between the nodes 3 and 4 .

Figure (3) shows the difference between the frequency response functions (FRF)

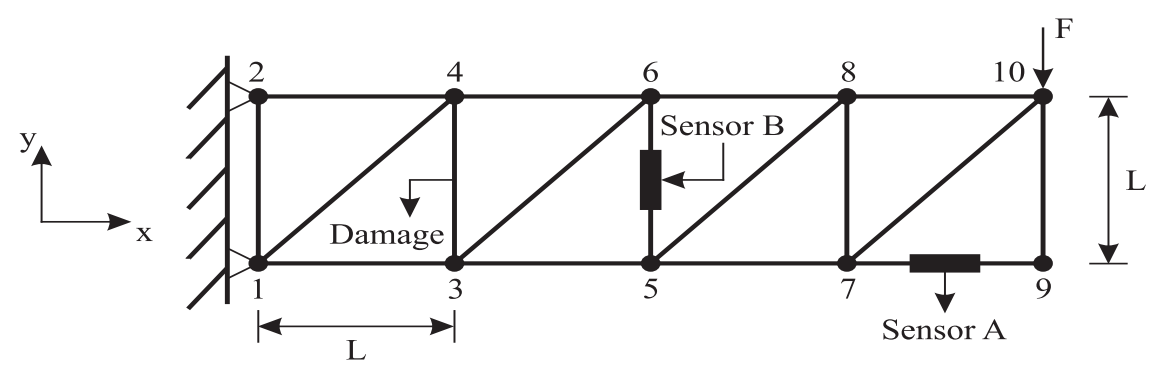

Figure 2: Plane truss structure discretized by FEM.

Table 1: Physical and geometric properties of the plane truss structure.

\begin{tabular}{|c|c|}
\hline Properties & Values \\
\hline \hline Young's Modulus $(\mathrm{GPa})$ & 210 \\
\hline Density $\left(\mathrm{kg} / \mathrm{m}^{3}\right)$ & 7850 \\
\hline L - length $(\mathrm{m})$ & 1 \\
\hline Transversal area $\left(\mathrm{m}^{2}\right)$ & 0,004 \\
\hline
\end{tabular}

of the plane truss structure with (FRF-a) and without damage (FRF-b). This difference occurs due to the change in the structural parameters with the presence 
of the damage. The five first modes of vibration are shown and the noise was not included.

Using sensor A, figure (4) shows the difference between the RMS (Root Mean

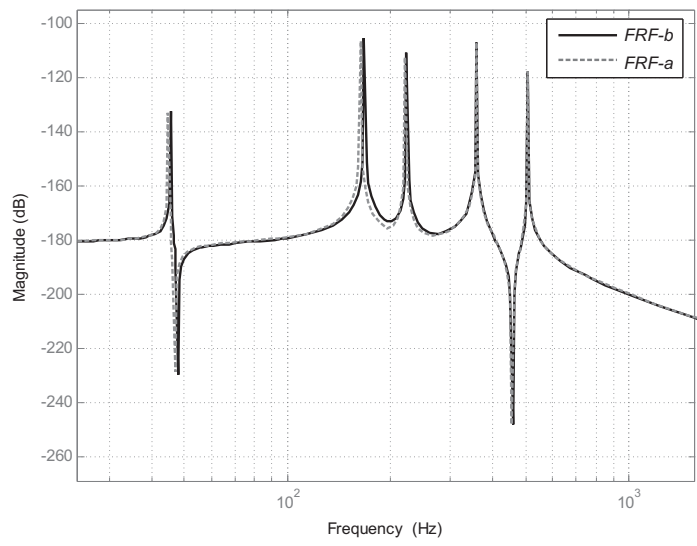

Figure 3: Frequency response function - FRF- $b$ and $F R F-a$.

Square) values of the modal displacement signal of the plane truss structure with and without damage for the five first vibration modes. It is possible to observe that the first and fifth modes are more affected by damage, respectively. Noise was not included in the input signal.

Figure (5a) presents the influence of the noise in the RMS values of the modal dis-

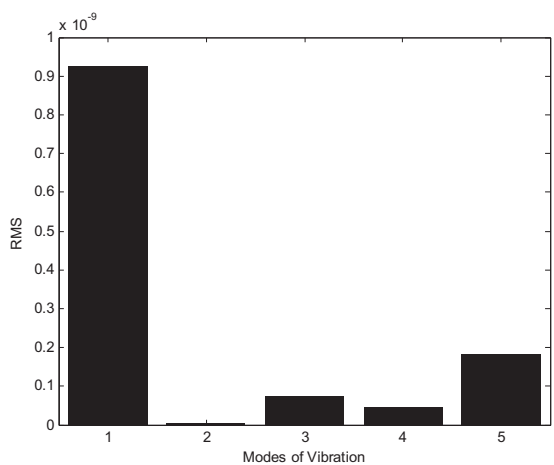

Figure 4: Vibration modes more affected by damage presence - considering the output displacement signals of the plane truss structure.

placement signals of the structure for the five vibration modes. Noise was included in the input signals, in order to verify the robustness of the proposal. It is possible to observe a variation in the RMS values with the noise influence in the first, fourth and fifth vibration modes. The RMS values for the second and third modes were not changed with the noise inclusion. The noise effect was applied only with the damage presence. Figure (5b) shows details of third, fourth and fifth modes. The 
fifth mode was the most affected by noise influence.

Figure (6) shows the difference between the RMS values of the modal velocity

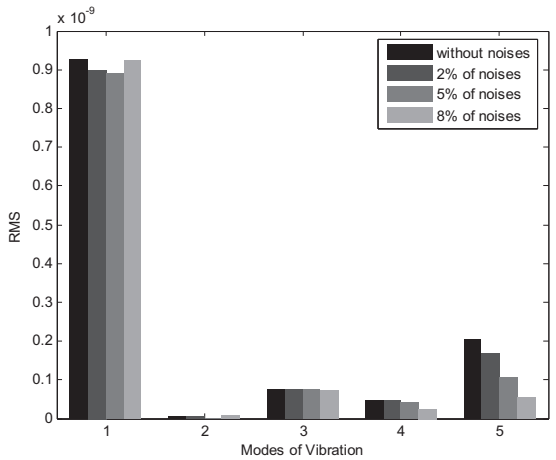

(a)

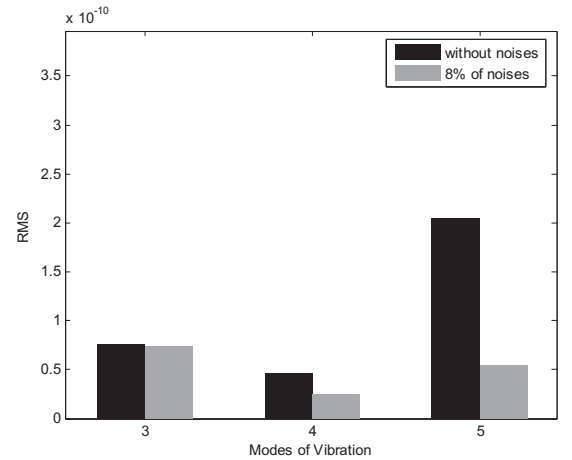

(b)

Figure 5: (a)Noise effect in the vibration modes - considering the output displacement signals. (b)Error found in the damage detection.

signal of the plane truss structure with and without damage. The five first vibration modes are shown and noise was not included in the input signal. It is possible to observe that the first and fifth modes are more affected by damage, respectively. Similar result was found when used displacement signals (figure (4)). Figure (7a)

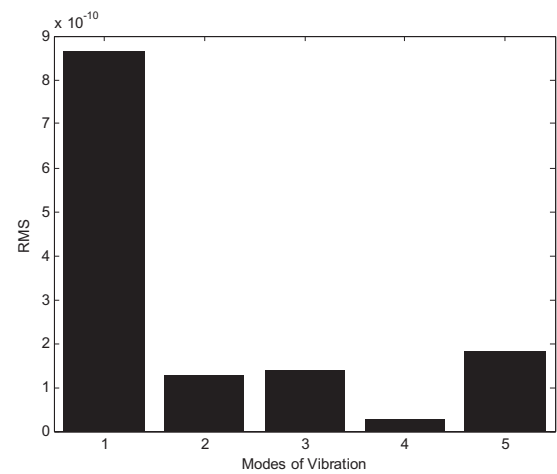

Figure 6: Vibration modes most affected by damage presence - considering the output velocity signals.

presents the influence of the noise in the RMS values of the modal velocity signals of the structure for the five vibration modes. Noise was included in the input signals. It is possible to observe a variation in the RMS values with the noise influence in the first and fifth vibration modes. The RMS values for the second, third and fourth modes were not changed with the noise inclusion. The noise effect was applied only with the damage presence too. Figure (7b) shows details of second, third, fourth and fifth modes. The fifth mode was the most affected by noise influence. 
The high difference found between the RMS values (displacement and velocity)

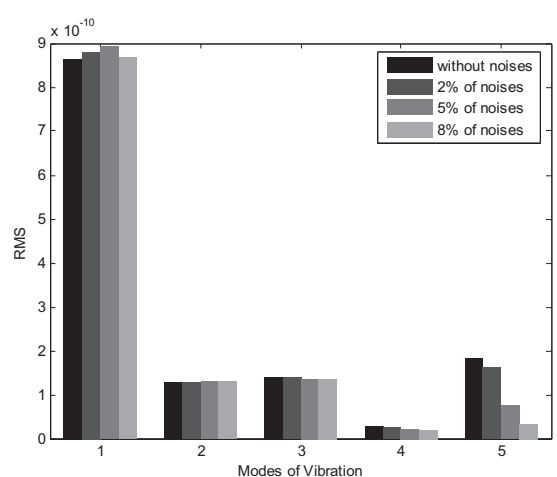

(a)



(b)

Figure 7: (a)Noise effect in the vibration modes - considering the output velocity signals. (b)Error found in the damage detection.

using the sensor A and sensor B considering the five modes of vibration was $1 \%$.

\section{Final Remarks}

Structural systems are susceptible of structural damage over their operating lives from impact, operating loads, and fatigue. Detecting the structural damage, leads to improved safety and offers the possibility of extending the service life of the structure by repairing components only when necessary. In this paper, the noises influence in the input signals of a plane truss structure was analyzed. The damage detection methodology using modal state observer was applied in order to verify the influence of the noise in the input signals. The increasing of noise causes a variation in the RMS values and it can lead to wrong diagnostic.

\section{Acknowledgment}

The authors are thankful to FAPESP - Fundação de Amparo à Pesquisa do Estado de São Paulo.

Resumo. Analisar os efeitos causados por ruídos nas metodologias de detecção de falhas trata-se de um importante assunto, por minimizar a probabilidade de ocorrer falsos diagnósticos. Neste trabalho, os efeitos causados por ruídos na detecção de falhas é estudado na metodologia de detecção de falhas através dos observadores de estado, baseados no domínio modal. Uma treliça plana e ruídos adicionados aos sinais de entrada foram utilizados.

\section{References}

[1] A.A. Cavalini Jr., D.D. Bueno, V.R. Franco, C.G. Gonsalez, E.H. Koroishi, V. Lopes Jr., G.P. de Melo, Sensitivity analysis of damage detection indexes 
for structural monitoring using modal state observers, in, "Proc. V National Congress of Mechanical Engineering", Salvador, 2008.

[2] A.A. Cavalini Jr., D.D. Bueno, V.R. Franco, C.G. Gonsalez, E.A. Perini, V. Lopes Jr., G.P. de Melo, Damage Detection through state observer approach, in "International Conference on Engineering Optimization", Rio de Janeiro, 2008.

[3] A.A. Cavalini Jr., E.H. Koroishi, A.F.G. Crespo, D.D. Bueno, C.R. Marqui, V. Lopes Jr., G.P. de Melo, Detecção de falhas simples e mútuas em uma viga Euler-Bernouli utilizando a metodologia dos observadores de estado, in "6 Brazilian Conference on Dynamics, Control and Their Applications", São José do Rio Preto, 2007.

[4] W. Gawronski, "Dynamics and Control of Structures, A Modal Approach", Springer Verlag, New York, 1998.

[5] S.R. Hall, The effective management and use of structural health data, in "Proceedings of the 2nd International Workshop on Structural Health Monitoring", pp. 265-275, 1999.

[6] E.M. Hernandez, D. Bernal, State estimation in structural systems with model uncertainties, Journal of Engineering Mechanics - ASCE, 134 (2008), 252-257.

[7] S.S. Kessler, S.M. Spearing, M.J. Atalla, C.E.S. Cesnik, C. Soutis, Structural health monitoring in composite materials using frequency response methods, in "Proceedings of the SPIE's 8th International Symposium on Smart Structures and Materials", Newport Beach, 2001.

[8] D.G. Luenberger, Observers for multivariable systems, IEEE Transactions on Automatic Control, AC 11 (1966), 190-197.

[9] D.G. Luenberger, Observing the state of a linear system, IEEE Military Electronics, MIL-8 (1964), 74-80.

[10] N.M.M. Maia, J.M.M. Silva, E.A.M. Almas, R.P.C. Sampaio, Damage detection in structures: from mode shape to frequency response function methods, Mech. Syst. Signal Process, 17, No.3 (2003), 489-498.

[11] N.M.M. Maia, J.M.M. Silva, J. He, N.A.P. Lieven, R.M. Lin, G.W. Skingle, W.To, A.P.V. Urgueira, "Theoretical and Experimental Modal Analysis", Research Studies Press Ltd., Baldock, 1997.

[12] G.P. de Melo, "Detecção e Localização de Falhas via Observadores de Estado de Ordem Reduzida", Doctor Thesis, FEM, UNICAMP, Campinas, SP, 1998.

[13] T.S. Moraes, "Diagnose de Falhas via Observadores de Estado com Excitações Desconhecidas, Identificadas por Funções Ortogonais", Master Thesis, DEM/FEIS, UNESP, Ilha Solteira, SP, 2002. 
[14] J.R.V. Moura Jr., V. Steffen Jr., D.J. Inman, Strength and damage characterization in an aircraft rib structure, in "IMAC-XXIV: A Conference and Exposition on Structural Dynamics", Society for Experimental Mechanics, 2006.

[15] G. Zhiwei, Actuator fault robust estimation and fault-tolerant control for a class of nonlinear descriptor systems, Automatica, 2007. 